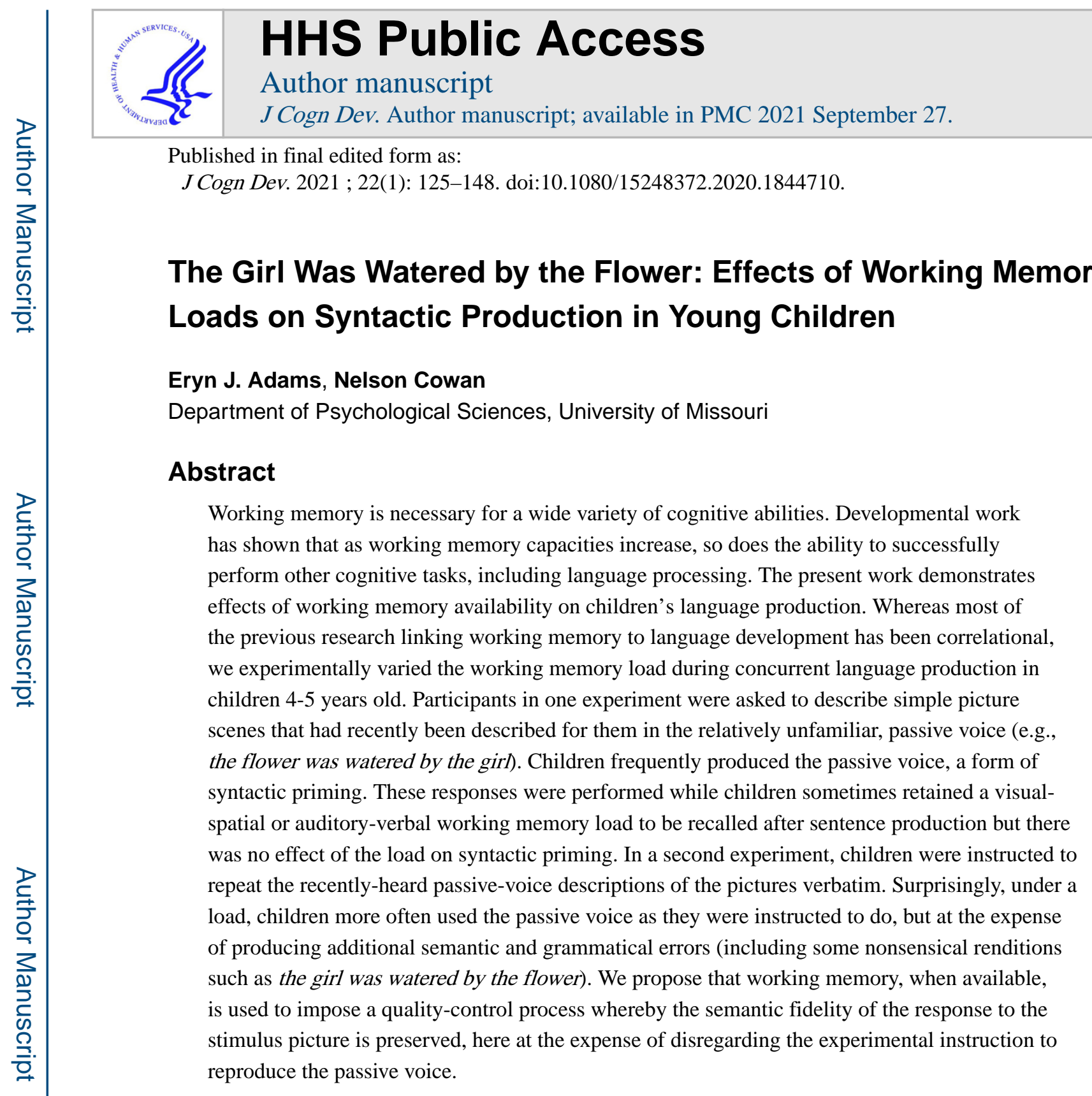

\title{
Keywords
}

sentence production; sentence repetition; passive sentences; working memory; memory load

\begin{abstract}
Here we examine effects of a working memory load on language production in children 4-5 years old. These children are the right age to ask for reproduction of a relatively novel syntactic structure, the passive voice in transitive sentences (those with a subject and direct object), as in the flower was watered by the girl. Such passive forms are difficult to process because the syntactic subject of the sentence (the flower) is semantically the patient, whereas the syntactic direct object (the girl) is semantically the agent or actor. In contrast, in the
\end{abstract}

(corresponding author) Send correspondence to Eryn J. Adams, Department of Psychological Sciences, McAlester Hall, University of Missouri, Columbia, MO 65211 USA. ejagf8@mail.missouri.edu.

Author Note

Materials and data for this study are available at https://osf.io/zd3b9/ and in the online supplement. 
more prevalent active, transitive form, the girl watered the flower, the subject is also the agent and the object is also the patient. Anyone who has traveled to where an unfamiliar language is spoken can attest to the difficulty of comprehension and production of novel forms, helping us to appreciate the linguistic novelty that children must deal with until their language systems reach maturity. In the present study, by sometimes requiring that the child remember some items unrelated to the passive sentence while producing it (i.e., a concurrent working memory load), we deprive the child of resources that might ordinarily be used to help process the sentence, so as to reveal the role of working memory in children's language production.

Working memory has many different definitions in the research literature (Cowan, 2017) but refers here simply to the small amount of information that can be held in an accessible state for use in cognitive tasks, including language production. It is clear that language use requires working memory, not only in comprehension (Daneman \& Carpenter, 1980; Just \& Carpenter, 1992) but also in the task of producing language, though there is much less research on the use of working memory during production (Bourdin \& Fayol, 1994; Acheson \& MacDonald, 2009). The connection between working memory and language processing also applies to children (Adams \& Gathercole, 1996; Archibald, 2018; Delage, \& Frauenfelder, 2019).

When an individual speaks, they must hold in mind the idea they are trying to convey while planning out the next few words in the utterance (cf. Cowan, 2014). Evidence for planning ahead in language production comes, for example, from research on slips of the tongue, in which individuals inadvertently reveal some of the current contents of working memory by making anticipatory errors (e.g., instead of an intended utterance, I will try the cake, saying I will cry the cake) or even switching segments (e.g., I will cry the take). Fromkin (1973) argued that such errors reveal a process in which speakers typically plan furthest ahead in terms of ideas and large linguistic units, planning sub-word segments at shorter lead times. Working memory is probably needed to plan ahead at all levels, as well as to monitor the plan for both linguistic and semantic accuracy compared to what was intended. We can find little extant evidence regarding the processes of planning ahead and monitoring speech production in children.

By imposing a memory load during children's delayed reproduction of passive sentence forms, we hoped to observe the role of working memory in dealing with linguistic novelty. Even in adults, a memory load to be recalled after sentence completion can result in syntactic errors, such as subject-verb agreement errors (Hartsuiker \& Barkhuysen, 2006). On each trial in our procedure, our interest is in how children retrieved and potentially reproduced the form of a sentence heard earlier to describe an image. In the first experiment, we explore how such recall of sentences is affected when the syntax can be influenced by priming. In the second experiment, we examine how such recall is affected when there are instructions to use the same syntax as the adult example. Both of these approaches mimic some aspects of ordinary language production, as sometimes children may pick up syntax structures, words, or phrases without intending to do so and other times they may deliberately aim to reproduce a certain syntactic form. 


\section{Theoretical Expectations}

The passive voice can be difficult to comprehend, especially for children (Huang et al., 2013, 2017; Turner \& Rommetveit, 1967) and this difficulty should carry over to production. Our choice of the age range of 4-5 years and use of the passive voice was motivated by research on the acquisition of the passive voice at this age. For example, Baldie (1976) found that children in this age range were able to imitate passive forms and comprehend them rather consistently, but still had difficulty with production of these forms. We used this age range under the assumption that these children require attention to keep passive structures in working memory. For younger children, these sentence structures may not be easily learnable whereas, for older children, these sentences might be memorable without much attention. To examine the effects of working memory loads on language production, 4 and 5 years thus seemed like a "sweet spot."

We chose two different types of working memory tasks at different set sizes to be used as loads during the language production task, based on the developmental literature: one auditory-verbal and one visual-spatial (for a review see Cowan, 2016; Adams et al., 2018). One load type, auditory-verbal, comprised a short list of spoken digits, which should be especially effective if there is a specialized auditory-verbal store (e.g., Baddeley, 1986). Another load type, visual-spatial, comprised the spatial locations of several tokens arranged within a $4 \times 4$ array of locations. This type of load should be consequential if there is an attention-dependent source of working memory storage that is not restricted to the verbal domain (Cowan, 2016), as should the auditory-verbal load. Thus, if a memory load operates by causing interference with the linguistic form, then only the digit span task should interfere with sentence production, but if a memory load operates by usurping attention that could otherwise be used in sentence production, then either type of memory load should be effective (especially the visual-spatial load, as it cannot be retained using well-learned words).

In sum, our questions of interest are as follows: When preschool-aged children are presented with a novel syntax that can influence their productions by way of automatic priming (Experiment 1) or when they are instructed to use the novel syntax deliberately (Experiment 2), how does the process interact with working memory? In particular, in each case, (1) How does requiring participants to maintain working memory loads affect the syntax of descriptions of transitive-action images? (2) Do different types of loads (i.e. visual-spatial vs. auditory-verbal loads) affect syntactic recall differently? (3) Do passive or active responses maintain meaning and/or verbatim accuracy when under load? Two hypotheses express different possible answers, each of which will be assessed in both experiments, which could yield different answers.

\section{Hypothesis 1: working memory allows complex responding.}

We initially expected that working memory loads would hinder complex syntactic production (correct use of the passive voice) compared to when there was no load. There are a couple different ways this change could occur. Our a priori hypothesis was that, when placed under a working memory load, participants would be more likely to use the active voice to recall what had been passive-voice descriptions of the events taking place in the 
images. Our reasoning was that, because the active voice is better known to children, it would require less working memory resources, and participants would thus be more likely to utilize this more familiar form when fewer working memory resources are available. With a working memory load, participants should be more likely to either switch to the active voice or use the passive voice incorrectly.

\section{Hypothesis 2: working memory allows semantically correct responding.}

An alternative, opposite possibility was that, under working memory load, participants would be more likely to use the passive voice. This could occur if the ordinary process of repetition actually involves a more elaborate process of understanding the sentence and then reconstructing the passive form of it. Under a working memory load, that process might become impossible and might be replaced with a more superficial process in which the passive form that was presented is simply repeated verbatim. This more direct, less memory-intensive mode of processing would come at a cost, however. Children would then be more susceptible to repetition errors that do not respect semantics (e.g., instead of correctly saying that the girl watered the flower, incorrectly saying that the girl was watered by the flower).

The alternative hypotheses about the effects of a working memory load of each type will be evaluated not only against each other, but also against the null hypothesis that working memory loads has no effect on language production. In favor of the null, linguistic processes could be autonomous (e.g., Caplan et al., 2007) or fully linguistic-knowledge-based, and therefore unaffected by a memory load.

\section{Experiment 1: Syntactic Priming of Passive Sentences Regardless of Memory Load}

Our first experiment was inspired by Huttenlocher et al. (2004), who found that children who were presented with sentences in the passive voice later sometimes used the passive in their own utterances in similar situations, a phenomenon called syntactic priming (also see Ambridge et al., 2015). Given that Huttenlocher et al. only obtained passive responses for a small minority of trials (in the first experiment, $15 \%$ of trials in which the model was passive), we tried to increase the number of passive-voice responses by presenting sentences as descriptions of the actions in pictures and then presenting the same pictures again, in hopes that the children would often use the same sentence form when asked to describe the same action.

\section{Method}

Participants.

Participants were young children from the Columbia, Missouri area. Eighteen participants completed Experiment 1 in full. Participants ranged from 4:0 to 6:2 $(M A=5: 1)$ and consisted of 11 females and 7 males. Eight of the participants were White or European, 5 were reported as being more than one race, 3 were Asian, 1 was American Indian, and 1 was unknown or not reported. Exclusion criteria required participants to have no uncorrected vision or hearing and to be native English-speakers. Participants were recruited from the 
community using a university-wide advertisement and received monetary compensation and a children's book.

\section{Design.}

Participants completed three trial blocks that varied by the type of working memory load (visual-spatial, auditory-verbal, or none). The visual-spatial block required participants to remember the location of 1,2, or 4 tokens depicted in a $4 \times 4$ matrix (Figure 1A). The auditory-verbal block required participants to remember a list of 1,2 , or 4 spoken digits. The third type of block contained no load, and participants were simply required to recall what occurred in each image, with no additional memory task. Participants began each block by listening to the experimenter describe 6 transitive-action drawings in the passive voice. This pre-exposure was followed by re-presentation of the pictures in a different random order, with the requirement that the child describe the actions. Half of the children received the trial blocks in the order, visual-spatial, auditory-verbal, then no load, whereas the other half received the order auditory-verbal, no load, then visual-spatial.

The order of the load sizes was 1, 4, 2, 1, 4 for visual-spatial loads and 1, 4, 1, 4, 2 for auditory-verbal loads. The difference in load-size presentation order proved inconsequential, inasmuch as no difference in results for the visual-spatial versus auditory-verbal load types was detected, either for all trials or for the first two trials for each load modality.

Following the main task, some auxiliary tasks were administered to gain a better understanding of relevant participant skills: the Peabody Picture Vocabulary Test $-4^{\text {th }}$ edition (PPVT-4; Dunn \& Dunn, 2007), the Expressive Vocabulary Test $-2^{\text {nd }}$ edition (EVT-2; Williams, 2007) and the simple digit span test.

\section{Stimuli.}

Participants were shown a total of 18 black and white drawings that depicted transitive actions drawn from a collection of line-drawings depicting transitive actions ( 3 served as practice trials; Szekely et al., 2004). Simple sentences (listed in the online supplement) were created by the experimenters to match the contents of the drawing (e.g., Figure 1, top, Panel B, "The ball was bounced by the boy."). Visual-spatial loads were created by depicting a gold token in 1, 2, or 4 boxes in a $4 \times 4$ matrix. All these stimuli were placed in a flip-book with dry-erase pages positioned like an easel, so that participants could draw their responses during the visual-spatial load trial block. For the digit load and span test, digits were spoken in a list intonation by the female experimenter at a rate of approximately one digit per second.

\section{Procedure.}

The experimenter began by saying the following to the participant: "First I'm going to show you some pictures of things that happened and describe them to you using only one sentence. You are going to describe pictures, too. Listen very carefully." Children heard 6 passive-voice descriptions of actions depicted on paper that could not reasonably be reversible, e.g., The cake was brought by the woman. They were not prompted or required to repeat the descriptions. Next, the instructions stated, "Now you'll describe some pictures 
like I did. But I'm going to have you try to remember something while you describe each picture."

In the visual-spatial block, after hearing the experimenter describe the drawings, they began with a practice trial in which they were told to try to remember where the one token was because they would be asked to draw its location later on. Then, they were presented with one of the images and asked to describe what they remembered occurring in the picture. Finally, they were shown a blank array of boxes identical to the one at the study phase and told to draw tokens (circles) in the boxes where they remembered seeing them. After the practice trial, the procedure was repeated for 5 test trials with the loads of 1, 2, or 4 items, varying as described in the Design section. In the auditory-verbal block, after hearing 6 new descriptions, participants would begin with a practice trial in which they were told they would try to remember one number spoken by the experimenter. The experimenter would state the number and then show one of the drawings for the participant to describe. After the participant's description of the drawing, they were asked if they could remember any of the spoken digits they heard before the drawing. This procedure was repeated for 5 test trials with the loads of 1,2 , or 4 items to be repeated in the presented order. The no load block would simply require participants to recall what happened in 6 new drawings, with one practice trial followed by 5 test trials.

\section{Auxiliary tasks.}

At the beginning of the session, participants completed the PPVT-4, which is a measure of receptive language. Participants are shown grids of 4 pictures and asked to point to the picture matching the word said by the experimenter. After the experimental portion, expressive language was also measured using the EVT-2, in which participants were shown one picture at a time and asked to name the picture using one word. Finally, participants completed the simple digit span test, which requires participants to repeat lists of digits in serial order, increasing in set size, until a ceiling is reached (in this case, three consecutive trials in which the participant cannot recall all digits). The highest set size in which all three lists were correctly recalled is taken as the participant's memory span.

\section{Results}

In our statistical analyses for both of the present studies, we use Bayesian t-tests and ANOVAS (Rouder et al., 2009, 2012). In particular, for each t or ANOVA effect, $\mathrm{BF}_{\text {incl }}$ is a Bayes Factor that reflects the likelihood of models containing the effect compared to the likelihood of models that are comparable (matched) except that they do not contain the effect. $\mathrm{BF}_{\text {incl }}$ values above 3.00 are considered to provide at least moderate support in favor of the presence of the effect in question, whereas $\mathrm{BF}_{\text {incl }}$ values below $1 / 3$ provide evidence in support of the null hypothesis of there being no effect. Those falling in between these values are considered indeterminate. We utilized the defaults of the JASP program (JASP team, 2019). For a more complete description of the results, here $\mathrm{BF}_{\text {incl }}$ values are supplemented with standard errors and two statistics from the standard ANOVA, F values and $\eta_{\mathrm{p}}{ }^{2}$, a measure of effect size. Using these tools, we examine active and passive sentence use and the effects of a memory load on it, correctness of this use and effects of the 
memory loads on it, correlations of sentence use and correctness with auxiliary measures, and performance on the memory load.

\section{Active vs. passive usage overall.}

First, we examined the use of the passive and active voice throughout all the participants' responses. A Bayesian paired-samples t-test showed no clear evidence for a difference between passive use $(M=0.33, \mathrm{SE}=0.07)$ and active use $(M=0.53, S E=0.08, \mathrm{t}(17)=$ $\left.-1.36, \mathrm{BF}_{\text {incl }}=0.53\right)$. In a third type of response, the participant did not answer using the active or passive voice (e.g., not in a sentence or verb phrase) or simply did not remember. These anomalous responses were the least frequent $(M=0.14)$ and did not differ by load type. Therefore, we focus on only passive or active responses for the remainder of these analyses.

Next, we examined if the different types of memory loads (visual-spatial, auditory-verbal, or no load) affected use of the passive or active voice. We found evidence against an effect of memory load on passive voice use, $\mathrm{F}(2,34)=0.01, \eta_{\mathrm{p}}{ }^{2}=.00, \mathrm{BF}_{\text {incl }}=0.15$, or active voice use, $\mathrm{F}(2,34)=0.21, \eta_{\mathrm{p}}^{2}=.01, \mathrm{BF}_{\text {incl }}=0.17$. In sum, a memory load did not alter the magnitude of the syntactic priming effect that induced use of the passive.

\section{Correct and incorrect use of passive and active voices.}

We further analyzed participants responses for the presence of errors, relative to the description initially heard. Active and passive responses were further divided up into the correct and incorrect use of those syntactic forms. Incorrect actives were those that expressed only part of the intended thought (e.g., The shoe was buckled by the man changed to Putting the shoe on) or expressed an incorrect or even impossible thought (e.g., The milk was paid for by the man changed to $A$ milk paid for the man). The same was true of uses of the passive voice, except that many of those uses involved reversing the roles of the nouns (e.g., The suitcase was dragged by the boy changed to The boy was dragged by the bag.) Overall, participants were most likely to use the active voice correctly $(M=0.38, S E=$ 0.07), compared to incorrect passive $\left(M=0.06, S E=0.04, \mathrm{t}(17)=3.54, \mathrm{BF}_{10}=16.89\right)$ and incorrect active $\left(M=0.14, S E=0.04, \mathrm{t}(17)=2.66, \mathrm{BF}_{10}=3.53\right)$ responses. Correct passive responses $(M=0.27)$ were the second most used type of response, but pairwise comparisons between these responses and the other three types were indeterminate.

In additional analyses, we analyze only correct responses except when the analysis of incorrect responses yields different answers. That can occur because correct and incorrect use of the active and passive forms does not account for all responses, leaving out anomalous responses that were neither active nor passive.

Load type did not affect the rate of occurrence of any of the response categories, but load size seemed to do so in one interesting case. When we analyzed incorrect active responses, we found that participants were the least likely to make these sorts of errors when they had no load. Compared to no load $(M=0.06, S E=0.04)$, pairwise comparisons revealed that participants were more likely to make these errors when they were under a load of 4 items, $M=0.19, S E=0.06, \mathrm{t}(17)=-3.09, \mathrm{BF}_{\text {incl }}=7.45 ; 2$ items, $M=0.22, \mathrm{SE}=0.07, \mathrm{t}(17)$ $=-2.86, \mathrm{BF}_{\text {incl }}=4.93$; or even just 1 item, $M=0.17, S E=0.06, \mathrm{t}(17)=-2.64, \mathrm{BF}_{\text {incl }}$ 
$=3.37$. The various load sizes did not differ from one another, however; all comparisons yielded an indeterminate effect $\left(1 \mathrm{vs} .2, \mathrm{BF}_{\text {incl }}=0.40\right)$ or evidence in favor of the null $(1 \mathrm{vs}$. $4, \mathrm{BF}_{\text {incl }}=0.27 ; 2$ vs. $\left.4, \mathrm{BF}_{\text {incl }}=0.26\right)$.

\section{Correlations with auxiliary measures.}

Most children also completed the PPVT-4 and EVT-2 as measures of vocabulary knowledge (3 participants did not complete the EVT due to fatigue towards the end of the session). The EVT-2 did not correlate with active voice use $\left(\mathrm{BF}_{\text {incl }}=0.32\right)$ and the other correlations between PPVT-4 or EVT-2 with either passive or active voice use fell within the indeterminate range. However, when assessing errors, we found that the higher participants scored on the PPVT-4, the more likely they were to utter correct sentences, $r(16)=0.77$, $\mathrm{BF}_{\text {incl }}=167.06$. We found a similar pattern for the EVT-2, in that better performance on this measure of expressive vocabulary also predicted more correct sentences, $r(13)=0.76$, $\mathrm{BF}_{\text {incl }}=40.13$. Individual differences in syntactic errors as a function of vocabulary skills is reassuring in that the age group we selected is, overall, neither too young nor too old to observe effects of load on syntactic performance.

We took measures of children's memory span using the simple digit span test (one participant did not complete this due to fatigue). We found indeterminate evidence for a correlation between digit span scores and active or passive use. However, we found that higher digit spans also predicted more correct production, $r(15)=0.62, \mathrm{BF}_{\text {incl }}=7.44$. Though higher digit spans seemed to also predict less incorrect production, this result was indeterminate $\left(r(15)=-0.34, \mathrm{BF}_{\text {incl }}=0.68\right)$.

\section{Load performance.}

We also analyzed performance on the load task itself to assess how it interacts with performance during the sentence component. Proportion of trials correct varied by type and size of the load (visual-spatial loads of one item, $M=0.58, S E=0.11$; two items, $M=$ $0.67, S E=0.11$; four items, $M=0.40=S E=0.07$; and auditory-verbal loads of one item, $M$ $=0.61, S E=0.10$; two items, $M=0.31, S E=0.09$; and four items, $M=0.46, S E=0.09$ ). Better performance on the load tasks did not correlate with passive voice use, $r(16)=0.08$, $\mathrm{BF}_{\text {incl }}=0.31$, and there was indeterminate evidence for a correlation with active voice use, $r(16)=0.25, \mathrm{BF}_{\text {incl }}=0.46$. However, we did find that better performance on the load task predicted more correct production, $I(16)=0.81, \mathrm{BF}_{\text {incl }}=697.72$.

\section{Discussion}

The syntactic priming effect inducing the use of the passive voice appears to have occurred as in Huttenlocher et al. (2004). However, the use of the passive was not successfully manipulated by the memory load, and it did not correlate with individual difference factors. The memory load did, however, cause more incorrect active sentences, suggesting that working memory may be needed to check that a production form matches the semantic situation. Moreover, measures of individual differences also related to the correct use of syntax. These results were encouraging inasmuch as they suggested that working memory is needed for correct language production. In the second experiment, we tried harder to obtain 
an effect of working memory load on the selected syntax by asking children to reproduce the relatively novel, passive forms that we presented.

\section{Experiment 2: Deliberate Syntactic Choices Altered by Memory Load}

The second experiment reflects an attempt to maximize the use of passives to learn whether, under these conditions, a memory load would matter. This aim was implemented with several changes. In Experiment 2, unlike Experiment 1, we added the request that the child should respond using the same way of speaking as the adult model. This change was intended to elicit attempts to use a new syntax whether or not the child felt completely comfortable with it, inasmuch as working memory might have a role precisely when the child is attempting to produce a novel grammatical form.

Several other changes in the experimental design went toward our aim. We added a practice portion composed of simple repetitions, so that the participant would be aware that the passive voice was the target syntax form that they must try to use throughout the experiment. We expected that the explicit request to emulate the speaking style of the experimenter, as well as the practice session, would be enough encouragement for the child to attempt to use the passive voice substantially more often in test trials than we found in Experiment 1. Additional stimuli were needed and the sentences describing the pictures are shown in the online supplement.

In this experiment we took into consideration the reversibility of the passives used to describe images. Reversible passives are those in which the agent and patient of the sentence can switch roles and the sentence will still be semantically plausible (e.g., the cow was pushed by the horse). Irreversible passives are those in which the agent and patient of the sentence cannot switch roles in a plausible manner (e.g., the flower was watered by the girl; a flower generally cannot water a girl; See Figure 1, top, Panel $\mathrm{C}$ for these examples of the modified stimuli). In order to examine how reversibility contributes to any recall effects, we used the normed nouns and verbs to create 12 reversible passive and 12 irreversible passive sentences.

Based on the results of Experiment 1, we decided on memory loads of two and three items to avoid ceiling and floor effects. We judged that with these set sizes, most children would have at least one set size for each modality for which performance is in a moderate range. We also expanded the number of trials from 15 to 24 in order to allow a balanced design. Auxiliary tasks were as in Experiment 1, except that it was necessary to omit the PPVT due to time constraints.

\section{Method}

\section{Participants.}

Participants were children from the Columbia, Missouri area. Judging from the results of the first experiment, the effect sizes could be smaller than originally anticipated so we doubled the sample size, in principle reducing the confidence interval of each mean to 0.71 of what it would have been. Thirty-six participants completed the experiment in full. Participants ranged in age from 4:0 to 5:11 (MA=5:0) and consisted of 21 females and 
15 males. Twenty-six of the participants were White or European, 4 were Asian, 1 was Hispanic, 2 were Black or African American and 3 were reported as more than one race. Exclusion criteria and compensation remained the same as in Experiment 1. The majority of participants were recruited from the community using a university-wide advertisement and postings to social media. A subset $(\mathrm{n}=12)$ were recruited from an on-campus researchfocused preschool, and these sessions were completed in a monitored room at the preschool.

\section{Design.}

As in Experiment 1, there remained an additional task of a memory load for two of the three experimental trial blocks: one block contained a visual-spatial load, and another block contained an auditory-verbal load. The third type of block again contained no load.

The order of trial blocks was governed by a Latin square with three orders for different groups of 12 participants: (1) visual-spatial, auditory-verbal, no load; (2) auditory-verbal, no load, visual-spatial; and (3) no load, visual-spatial, auditory-verbal. In each trial block, the order of 8 pictures during the initial presentation of sentences was unrelated to the order of these same 8 pictures during the test trials. Each of the three trial-block-order groups was split in half according to the order of the 24 pictures throughout test trials in the experiment. There were two picture orders, such that the picture order within each trial block included four Reversible (R) and four Irreversible (I) sentences: RIRRIIRI versus IRIIRRIR. Given the use of only two picture/sentence orders in the experiment despite counterbalanced ordering of loads, each picture was presented equally often in each memory load condition. In the conditions in which there was a memory load, the 8 pictures for that order were used in trials always starting with a memory load of 2 items and alternating across trials between 2 and 3 items.

\section{Stimuli.}

Transitive action images were formed by piecing together free digital drawings or images to depict the subject and object of the transitive-action description. For example, an image with the description, The lion was stopped by the bear would only depict a lion and a bear, not the verb. Most picture pairs we were able to assemble potentially biased the perceived action in one direction and, when this occurred, we consistently selected the direction of action that most naturally went with the picture (e.g., assigning an actor role to an animal seeming to look at the other and a patient role to the animal looking elsewhere). As a result, effects of reversibility should be considered as conservative estimates of those effects. The verb of the description could not be deduced by simply looking at the images, as they were still-images and most verbs could not be guessed due to the absence of contextual clues. Additionally, we counterbalanced the positioning of the images so that 11 images had the agent on the left side, 12 had the agent on the right, and 1 featured the agent holding the patient. These color images were displayed on a 7- x 10-inch, light gray background. All participants viewed the images on a laptop screen, placed on a desk at eye-level. Instructions and descriptions were all read aloud by the experimenter.

Agent and patient names and verbs used for image descriptions were selected from words known by the end of the $5^{\text {th }}$ year according to age-of-acquisition norms (Kuperman, 
Stadthagen-Gonzalez, \& Brysbaert, 2012; Bird, Franklin, \& Howard, 2001). Agents, patients, and verbs were not repeated within an experimental block, but some agents or patients and verbs were used twice, given the low number of words available that could be used in a transitive sentence and also displayed in a simple image (see online supplement for the list of sentence stimuli). Once these sentences were formed, we created the visual stimuli using free digital images from an online collection to display the agent and patient of the transitive action (https://www.picpng.com).

For this experiment, only visual-spatial loads were displayed in a flipbook positioned like an easel so that participants could draw responses with a dry-erase marker. During visualspatial loads, the visual-spatial book was placed beside the laptop screen, but close enough for the participant to draw responses. Auditory-verbal loads were digits spoken by the experimenter in a list intonation at a rate of approximately $1 \mathrm{~s} /$ digit.

\section{Procedure.}

The procedure of Experiment 2 closely followed that of Experiment 1, with a few key exceptions. Unlike Experiment 1, participants were first told that the experimenter would be using a "special way of talking," and that they were to listen very carefully and try to speak the same way while they looked at and described the pictures. They were then told they would do some practice to understand what was meant by a special way of talking. Participants were asked to simply repeat 5 passive voice sentences after the experimenter (e.g., The lollipop was eaten by the mom). Next, participants were told they would see how to use the special way of talking to describe pictures. They were shown 5 images depicting an agent and patient and repeated passive voice descriptions spoken aloud by the experimenter. After this practice session, participants were told they would begin by listening to descriptions of more pictures. However, this time, they were not required to repeat the descriptions immediately, but only to try and remember what was said about each, because they would be asked later. Experimental sessions were audio-recorded for later transcription. In Figure 1 (bottom), we provide an example of how one trial would proceed within each of three types of trial blocks: one with a visual-spatial working memory load, one with an auditory-verbal working memory load, and one with no load.

Each trial block proceeded the same as with experiment one, except each load block began with two practice trials without an additional language task. Then, after the experimenter descriptions of 8 images, there were 8 test trials in each block.

\section{Auxiliary tasks.}

Finally, as with Experiment 1, participants also completed a simple digit span test as well as the Expressive Vocabulary Test-Second Edition (EVT-2; Williams, 2007; The PPVT-4 was deemed less important than the expressive test, the EVT-2, and omitted because of time constraints.).

For participants who completed sessions in our laboratory space, sessions were completed in roughly one, continuous, 45-minute session. For participants who completed sessions at the on-campus preschool, sessions were split into two, completing the entire experimental 
portion within the first session and the vocabulary and digit span assessments in a second session.

\section{Results}

Our goal in analysis was to understand the effects of memory load on syntactic usage. Any effect that applies to a visual load should result from the sharing of attention between the load and sentence production in our task, whereas any effect that is specific to a verbal load should result from language interference with the sentence production task. The pattern of load effects therefore should indicate what processes are necessary for sentence production. We first examine the overall use of active versus passive sentences. Then we examine the effects of memory load, followed by the interaction of load and sentence reversibility in affecting the use of actives versus passives. After that, in separate analyses, we dissect the active and passive responses to determine how often they were used correctly versus incorrectly, with or without a memory load. Then we describe the error types in further detail and assess the overall effect of load on the correct expression of the semantics of the experimenter's model sentence. Last, we examine the relation of sentence production to auxiliary measures.

\section{Active vs. passive usage overall.}

We first examined if participants used the passive or active voice more, regardless of load condition, using a paired samples t-test. The results are summarized in Figure 2. Overall, participants utilized the passive voice in their descriptions $(M=0.65, S E=0.05)$ more than the active voice $\left(M=0.26, S E=0.04, \mathrm{t}(35)=4.48, \mathrm{BF}_{\text {incl }}=317.66\right)$, indicating an understanding of the task at hand, which was to use the same form of speaking as the experimenter.

\section{Effects of memory load.}

We then examined how load condition affected the proportion of passive versus active voice usage using Bayesian, repeated-measures, one-way ANOVAs. One factor included within each type of working memory load condition was the load size of either 2 or 3 items. We examined if load size differences affected passive and active sentence use with Bayesian repeated measures one-way ANOVAs. For visual-spatial load, there was evidence against an effect of load size on passive usage $\left(\mathrm{F}(1,35)=0.215, \eta_{\mathrm{p}}{ }^{2}=0.01, \mathrm{BF}_{\text {incl }}=0.26\right)$ or active usage $\left(\mathrm{F}(1,35)=0.285, \eta_{\mathrm{p}}{ }^{2}=0.01, \mathrm{BF}_{\text {incl }}=0.28\right)$. For auditory-verbal loads, there was also no evidence for an effect of load size on passive usage $\left(F(1,35)=0.00, \eta_{p}{ }^{2}=0.00, B F_{\text {incl }}=0.24\right)$ or active usage $\left(\mathrm{F}(1,35)=0.00, \eta_{\mathrm{p}}{ }^{2}=0.00, \mathrm{BF}_{\text {incl }}=0.24\right)$. Thus, in the remaining analyses, we collapsed the evidence across load size.

When assessing passive voice usage, there is strong support for a main effect of load type $\left(\mathrm{F}(2,70)=9.71, \eta_{\mathrm{p}}{ }^{2}=0.22, \mathrm{BF}_{\mathrm{incl}}=129.32\right)$. Further pairwise comparisons revealed that, opposite to our initial Hypothesis 1 but favoring the alternative Hypothesis 2, the proportion of passive usage by participants was higher in the visual-spatial load condition ( $M=0.73$, $S E=0.05)$, than in the no-load condition $\left(M=0.55, S E=0.05 ; \mathrm{BF}_{\text {incl }}=101.05\right)$. There was only indeterminate support for a difference between the auditory-verbal load condition 
$(M=0.67, S E=0.06)$ and the no-load condition $\left(\mathrm{BF}_{\mathrm{incl}}=2.29\right)$. There was also no support for a difference between the visual-spatial and auditory-verbal conditions $\left(\mathrm{BF}_{\mathrm{incl}}=1.41\right)$.

For active voice usage, there is also strong support for a main effect of load type $\left(\mathrm{F}(2,70)=13.06, \eta_{\mathrm{p}}{ }^{2}=0.27, \mathrm{BF}_{\mathrm{incl}}=1259.27\right)$. Pairwise comparisons revealed that, against our initial expectations (Hypothesis 1) and favoring the alternative Hypothesis 2, the proportion of active usage was higher in the no-load condition $(M=0.38, S E=0.05)$ than in the visualspatial condition $\left(M=0.18, S E=0.05, \mathrm{BF}_{\text {incl }}=677.58\right)$. Also against our initial expectations, participants appeared to use the active more under no load than when under auditory-verbal load ( $\left.M=0.23, S E=0.05, \mathrm{BF}_{\text {incl }}=8.92\right)$. Finally, there was no support for a difference in active voice usage between the visual-spatial and auditory-verbal load conditions $\left(\mathrm{BF}_{\text {incl }}=0.75\right)$.

A third category of response in addition to active and passive voice responses were those in which the participant simply forgot what occurred in the image all together, did not respond, or produced answers that did not clearly fall into either the active or the passive categories expressing the type of action stated in the experimenter's model sentence. These types of responses were relatively infrequent $(M=0.09)$ and there appeared to be no main effect of load type on the occurrence of these responses $\left(\mathrm{F}(2,70)=0.59, \eta_{\mathrm{p}}{ }^{2}=0.02, \mathrm{BF}_{\text {incl }}=0.14\right)$. For these reasons, we focus on only responses that clearly fell into the two main categories of interest (passive or active) for the remainder of analyses presented.

\section{Load type and reversibility.}

We examined how both load type and sentence reversibility affected passive and active voice usage, with Bayesian repeated measures two-way ANOVA. If semantic information is correctly used to guide the construction of passive sentences, one would expect that irreversible sentences would result in more passive sentence usage, especially under a memory load. Our results did not support that expectation, as shown in Figure 2.

For passive voice usage, as supported by earlier analyses, there appeared to be a main effect of load type. However, there was evidence against the inclusion of reversibility in the model $\left(\mathrm{F}(1,35)=0.41, \eta_{\mathrm{p}}{ }^{2}=.01, \mathrm{BF}_{\text {incl }}=0.18\right)$ or an interaction of the two factors $\left(\mathrm{F}(2,70)=0.51, \eta_{\mathrm{p}}{ }^{2}=.01, \mathrm{BF}_{\mathrm{incl}}=0.12\right)$, suggesting that the reversibility of sentences did not affect participants' use of the passive voice. For active voice usage, there was extreme evidence for a main effect of load type as supported by the earlier analyses. There was indeterminate support for a main effect of reversibility $\left(F(1,35)=8.03, \eta_{\mathrm{p}}{ }^{2}=0.19\right.$, $\left.\mathrm{BF}_{\text {incl }}=2.27\right)$. There was indeterminate support for an interaction between the two factors of load type and reversibility $\left(\mathrm{F}(2,70)=2.62, \eta_{\mathrm{p}}{ }^{2}=0.07, \mathrm{BF}_{\text {incl }}=0.41\right)$. A clearer effect of reversibility emerges below, where we describe the correct use of the active voice.

\section{Correct and incorrect use of passive and active voices.}

Additional expectations had to do with whether a construction was used correctly when it was used. Figure 3 provides a summary of these results. Although our expectation that the passive voice would be used less often under a memory load was not confirmed (it was actually used more often under load), it remained possible that the additional use under load entailed more errors (uses of language that did not reflect the correct meaning). This could 
occur if a memory load impaired a child's ability to avoid the passive voice when uncertain about how to use it or construct it correctly.

We examined, when participants used the passive voice, if their utterance maintained the intended meaning, and if this varied by load type and the reversibility of the sentence. For example, if they heard an image described as The flower was watered by the girl, an incorrect repetition would be The girl was watered by the flower. Incorrect responses would also be those in which the participant recalled the agent and/or patient incorrectly. (A breakdown of all types of incorrect responses is included in the online supplement.) Truncated passives (e.g., The flower was watered) were allowed as utterances that did maintain meaning.

We assessed instances in which participants used the passive voice correctly. We found that there was marginal support for a main effect of load type $\left(F(2,70)=4.10, \eta_{\mathrm{p}}{ }^{2}=.11\right.$, $\mathrm{BF}_{\text {incl }}=2.73$ ) when compared against the null model. As with analyses of all passive voice responses, participants used the passive voice correctly more when under visual-spatial load $(M=0.60, \mathrm{SE}=0.05)$ as compared to when there was no load $(M=0.47, \mathrm{SE}=0.05$, $\left.\mathrm{BF}_{\text {incl }}=5.48\right)$. There was no evidence for a difference between auditory-verbal loads $(M=0.56, S E=0.06)$ and no load $\left(\mathrm{BF}_{\text {incl }}=0.75\right)$ or a difference between visual-spatial and auditory-verbal loads $\left(\mathrm{BF}_{\text {incl }}=0.25\right)$. There was evidence against including the factor of reversibility $\left(\mathrm{F}(1,35)=0.02, \eta_{\mathrm{p}}{ }^{2}=.00, \mathrm{BF}_{\text {incl }}=0.15\right)$ or an interaction term $(\mathrm{F}(2,70)=0.57$, $\left.\eta_{\mathrm{p}}^{2}=.02, \mathrm{BF}_{\text {incl }}=0.13\right)$.

We also examined correct versus incorrect use of the active voice by load type and the reversibility of the sentence. For example, if children heard an image described as The flower was watered by the girl, an incorrect use of active would be, The flower watered the girl. Correct use of the active would be, The girl watered the flower. In analysis of cases in which participants used the active voice correctly, we found very strong evidence for a main effect of load type $\left(\mathrm{F}(2,70)=13.21, \eta_{\mathrm{p}}{ }^{2}=.27, \mathrm{BF}_{\text {incl }}=44,450.76\right)$, in that participants used the active voice correctly more often when there was no load $(M=0.34, S E=.05)$ than when there was a visual-spatial load $\left(M=0.15, S E=0.04, \mathrm{BF}_{\text {incl }}=2087.63\right)$, as well as when there was an auditory-verbal load $\left(M=0.18, S E=0.04, \mathrm{BF}_{\text {incl }}=86.20\right)$. There was no difference between the visual-spatial and auditory-verbal loads $\left(\mathrm{BF}_{\text {incl }}=0.28\right)$. There was also an effect of reversibility $\left(\mathrm{F}(1,35)=14.91, \eta_{\mathrm{p}}^{2}=.30, \mathrm{BF}_{\text {incl }}=37.29\right)$ in that participants used the active voice correctly more often when the sentence was not reversible $(M=0.28, S E=0.04)$ than when the sentence was reversible $\left(M=0.17, S E=0.03, \mathrm{t}(35)=3.86, \mathrm{BF}_{\text {incl }}=82.30\right)$. There was indeterminate evidence for an interaction between the two factors $\left(F(2,70)=4.38, \eta_{\mathrm{p}}{ }^{2}=.11\right.$, $\left.\mathrm{BF}_{\text {incl }}=1.55\right)$. Nevertheless, Figure 3 makes it clear that the increase in correct active sentences occurred to a greater extent in the case of irreversible sentences. The result further provided evidence for the hypothesis of children using more familiar (and more correct) speech when there is no additional load to be handled, consistent with Hypothesis 2.

We created categories of the types of errors that were revealed in participant responses (see online supplement for specific categories). We found that while $39.2 \%$ of these errors occurred when the sentence was not reversible (e.g., the flower was watered by the gir), the other $60.8 \%$ of errors occurred when the sentence was reversible (e.g., the cow was 
pushed by the horse). Within these errors, a substantial portion were errors in which the participant switched the syntactic role of the patient and agent (e.g., the girl was watered by the flower). These errors were more likely to occur when the sentence was reversible: $40.2 \%$ of these types of errors occurred when the sentence was not reversible and the remaining 59.8\% when the sentence was reversible. When excluding errors that were only verb related, these role-reversing errors made up the vast majority of syntactic errors (57\%). This sharply contrasted our results from Experiment 1 in which the majority of errors were semantically deviant. These reversal errors deal more with an issue at the level of syntactic roles with concomitant semantic consequences (e.g., the girl pulling the dog rather than vice versa), whereas in Experiment 1, participants more often produced more drastic semantic differences from the adult model that was provided (e.g., the dog and girl going for a walk).

What is the overall effect of the memory load on errors, regardless of the type of error? We examined this issue by adding together correct active and correct passive responses and examining them as a proportion of all responses. The results indicate the success of children in conveying the semantic role relationship in the experimenter's model sentences, whether stated in the active or passive voice. For irreversible sentences, load made a big difference in this key regard, $\mathrm{F}(2,70)=6.13, \eta_{\mathrm{p}}{ }^{2}=0.15, \mathrm{BF}_{\text {incl }}=10.03$. Pairwise comparisons showed that the no-load condition resulted in a proportion correct $(\mathrm{M}=.90, \mathrm{SE}=.03)$ higher than the visual-spatial load condition $\left(\mathrm{M}=.79, \mathrm{SE}=.05, \mathrm{BF}_{\text {incl }}=5.77\right)$, and higher than the auditoryverbal load condition $\left(M=.77, S E=.05, \mathrm{BF}_{\text {incl }}=6.44\right)$, though the latter two did not differ $\left(\mathrm{BF}_{\text {incl }}=0.21\right)$. For the reversible sentences, though, load made no difference $\left(\mathrm{BF}_{\text {incl }}=0.10\right.$, or 10 to 1 in favor of the null hypothesis; no-load, $M=.73, S E=.05$; visual-spatial load, $S E=.70$, $S E=.05$; auditory-verbal load, $M=.71, S E=.06$ ). From Figure 3 it is clear, moreover, that the extra correctness in irreversible passives with no memory load occurred almost entirely from additional, correct active sentences (rightmost bar in the bottom panel of the figure), and occurred despite the fact that the proportion of correct passives was smaller than in any other condition in the experiment.

\section{Correlations with auxiliary measures.}

We also gathered a measure of expressive vocabulary via the EVT-2. (Two participants did not complete this due to fatigue or moving away between sessions). Using a Bayesian correlation pairs analysis, there seemed to be evidence of a correlation between EVT scores and passive $\left(r(32)=0.45, \mathrm{BF}_{\text {incl }}=6.04\right)$, but indeterminate evidence for a correlation with active voice use $\left(r(32)=-0.31, \mathrm{BF}_{\text {incl }}=0.97\right)$. We also found that EVT scores correlated with more correct use of the passive voice $\left(r=0.58, \mathrm{BF}_{\text {incl }}=113.37\right)$. We analyzed correlations of digit span with several factors. (Four participants did not complete this test due to fatigue or moving away between sessions). We found that digit span scores strongly predicted whether participants would utter correct sentences $\left(r(30)=0.55, \mathrm{BF}_{\text {incl }}=35.36\right)$.

\section{Load performance.}

Another factor to consider was how participants performed on the memory load. For visual-spatial loads, we assessed the proportion of correctly placed tokens out of the number possible (i.e., two or three). When assessing auditory-verbal loads, we considered a conservative coding scheme in which participants' responses were coded for correct serial 
order. Results revealed low performance levels $(\mathrm{M}=0.23)$ which did not correlate strongly with visual-spatial load performance $\left(r(34)=0.30, \mathrm{BF}_{\text {incl }}=0.90\right)$. Thus, for comparability between tasks, we assessed the number of digits participants correctly recalled, without strict requirements for digit order (e.g., participants could recall " $3,2,1$ " as " $1,2,3$ "). Participants' performance on the two different types of loads ( $M=0.44$ for visual-spatial and $M=0.35$ auditory-verbal) strongly correlated $\left(r(34)=0.50, \mathrm{BF}_{\text {incl }}=21.06\right)$, providing evidence that the two different load types were relying on similar resources or abilities.

Load performance did not correlate with passive $\left(r(34)=0.25, \mathrm{BF}_{\text {incl }}=0.59\right)$ or active voice use $\left(r(34)=-0.22, \mathrm{BF}_{\text {incl }}=0.47\right)$. We also found that load performance did not strongly predict if participants would have more correct use of sentences $\left(r(34)=0.14, \mathrm{BF}_{\text {incl }}=0.29\right)$. The same held true when we split these responses by syntax.

\section{Discussion}

The second experiment differed from the first in that the first experiment relied on syntactic priming to elicit passive sentences, whereas the second experiment elicited passive sentences through deliberate instruction. The main difference in the findings was that, whereas the first experiment produced no evidence of an effect of a memory load on syntactic priming, the second experiment did produce effects of a memory load on the deliberate use of the passive. This effect was clearest for visual memory loads, showing that the load effects were most likely to be related to attention, not to verbal interference specifically. Moreover, the load effects clearly favored one of our hypotheses over another. With a memory load, children were more likely to use the passive voice, not the active. This finding indicates that despite our instruction to use the passive, imitating the experimenter's previous description, children had a different first priority of getting the semantics correct. They could do this well when there was no memory load by processing the sentence and constructing a sentence (often in the active voice) expressing the message. Under a memory load, children showed that they could remember and repeat the passive form that had been presented, but more often presumably without the same check to ensure that the form was used correctly, sometimes resulting in errors such as The girl was watered by the flower.

\section{General Discussion}

Previous work has shown how working memory capacity is related to language skills, but little work has used an experimental approach to assess the effect of a memory load on language production. We found no such work in children. In the present study with children 4 to 5 years old, we examined the effect of an auditory-verbal or visual-spatial working memory load on the syntax of children's repetition of recently-heard passive sentences. Children heard these sentences in reference to illustrations of transitive actions, and later were to produce their own descriptions of the illustrations.

In Experiment 1, children sometimes used the passive voice that they ordinarily would not use at this age but heard the experimenters produce, a type of syntactic priming and a conceptual replication of Huttenlocher et al. (2004). However, there was no effect of a memory load on children's choice of the syntactic form. We surmised that syntactic priming may occur outside of the need for working memory, a result consistent with views of 
syntactic processing that are modular and relatively autonomous rather than integrated with the working memory system (e.g., Caplan, Waters, \& DeDe, 2007).

Consequently, in Experiment 2 we did not use syntactic priming, but instead explicitly asked children to try to emulate the same form of speaking as the experimenter. Our goal was to encourage children to utilize the passive voice, a somewhat novel structure for children of this age. We considered that deliberate usage of a novel form would require working memory. Participants did use the passive voice in their recalled descriptions considerably more than the active voice, verifying that the instructions were generally understood.

There was an effect of working memory load, though not in the way we had anticipated (i.e., contrary to Hypothesis 1 in the introduction). In particular, Experiment 2 showed the following: (1) Consistent with Hypothesis 2, participants were more likely to use the passive voice when they had to maintain a visual-spatial load, as compared to when there was no additional load. (2) Also consistent with Hypothesis 2, participants were more likely to use the active voice when they did not have to maintain an additional load (be it visual-spatial or auditory-verbal). (3) Participants were more likely to use the active voice correctly when there was no load. This was especially true in instances where the sentence was not reversible (see Figure 3). (4) Overall, participants were less likely to make errors deviating from the stimuli semantically when they did not have to maintain an additional memory load. (5) In contrast, though, a memory load diminished a different kind of departure from instructions, namely choosing the active form when instructed to use the passive. Below, we comment further on the possible interpretation of these findings.

\section{Selection of active versus passive voice.}

A key finding was that participants were more likely to use the passive voice when there was a visual-spatial load compared to when there was no extra load to remember and, conversely, more likely to use the active voice when under no load, when compared to both visual-spatial and auditory-verbal loads (Figure 2). According to the rationale associated with Hypothesis 2, it actually takes more working memory to make the effort to ensure that semantic errors are avoided, rather than to produce the same syntactic form as the experimenter. Children could make semantically more accurate responses, with nouns appropriately assigned to the actor and patient roles in the same way as in the experimenter's sentence, by remembering and processing the picture's description at a semantic level and then converting the remembered relation into a sentence, which is likely to be an active sentence if the participant does not feel compelled to use the experimenter's modeled syntax. In contrast, under a memory load, children presumably do this deep processing less often or less completely, and instead more often simply try to produce the surface form matching what the experimenter said, a passive voice that was more often used incorrectly, with switched roles of the actor and patient.

It is an often-repeated maxim that young children attend to the meaning of utterances at the expense of attending to syntax when instructed by adults. This point is supported by myriad examples of children's failure to attend to syntax when being corrected by adults. One example is a child saying something like, I goed to my bedroom, an adult response like, You should say 'I went to my bedroom', and a child's response like, That's what I said, I 
goed to my bedroom. Gleitman et al. (1972) found that the ability to attend to syntax rather than semantics only begins to emerge around the age range of participants in the present study. For example, a 3-year-old presented with a "silly sentence," Bring cup, corrected it not as Bring the cup or Bring me the cup, but rather as Drink from the cup. It would be in line with the phenomenon of children's developing grammatical awareness if the present instructions were interpreted by children in a manner in which semantics were considered more important than syntax. The use of working memory resources to produce semantically accurate forms, as opposed to focusing on syntactically accurate forms, seems evident also in young children's spontaneous language production. For example, two-year-olds have been shown to omit common function morphemes from their speech despite evidence of successful comprehension of these elements (Gerken et al., 1990). We suggest that, with a limited working memory, young children may selectively omit less-important elements of adult syntax in order use their available working memory to ensure the semantic correctness of what they say.

\section{Semantic correctness of utterances.}

Another key result was that participants utilized the active voice correctly more often when the sentence was not reversible (e.g., the banana was eaten by the monkey), especially under no memory load (Figure 3). Irreversible passives have been shown to be easier for children to interpret than reversible passives, partially because of the nature of only being interpreted one way (Harris, 1976; Hutson \& Power, 1974; Sinclair, Sinclair, \& DeMarcellus, 1971). While the agents of the reversible sentences could be switched and still make logical sense, this is not the case with irreversible sentences.

It might have been expected that reversibility would make the most difference for memory load conditions, rather than for the no-load condition as Figure 3 suggests. The finding we obtained does not suggest that children were very concerned about reversing the roles of the nouns in reversible sentences, but rather with doing so in irreversible sentences. Thus, with no memory load, the active voice was used more frequently especially for irreversible sentences. One way that this pattern would make sense is if children were not very concerned with the possibility of reversing the order of nouns within reversible sentences, which would result in another plausible interpretation of the picture (e.g., the cow pushing the horse rather than vice versa). They apparently were more concerned with producing a sentence in which a reversal would result in a silly statement (e.g., the flower watering the girl rather than vice versa).

Aside from the fact that reversal of an irreversible sentence produces a nonsensical meaning, it may go against a natural tendency for the actor to be considered or stated before the patient, a preference seen in young children's interpretation of sentences within languages in which the word order is more flexible than in English (e.g., in Japanese: Hakuta, 1982; and in Tagalog: Segalowitz \& Galang, 1978). We do not know if our finding in this regard would have been different had we included sentences like the ball hit the dog, in which action is attributed to an inanimate noun. The static nature of these pictures might have also affected how often children were more likely to produce errors and reverse the agent and patient of the picture. Future studies could change this by adding more dynamic pictures or animations 
that show the action itself. If working memory loads still affect children's production, this could have even stronger implications for the role of working memory, as children should have an easier time recalling the direction of an action as they watch it.

\section{Differences between load types.}

It was found that visual-spatial loads were more consistently effective in altering syntactic preferences and semantic correctness, compared to auditory-verbal loads (see Figures $2 \&$ 3). This finding is informative about the kinds of working memory processes that could have interfered with performance. Clearly, verbal loads are more effective than visual-spatial loads in interfering with phonological processing (e.g., Baddeley, 1986). However, visualspatial loads are more dependent on general attention (Morey \& Bieler, 2013), perhaps because there is no visual-spatial equivalent of a well-learned set of auditory-verbal routines for maintaining information in working memory, leaving only attention as the mechanism of refreshing visual-spatial information (cf. Camos, Mora, \& Oberauer, 2011). For example, in one study of 9-year-old children providing structural equation modeling of results from a variety of working memory tasks, there was a difference between auditory-verbal memory tasks that did versus did not lend themselves to rehearsal processing. Whereas standard digit span does allow rehearsal and loaded with phonological processing tasks, running digit span (with an uncertainty about when a long list will end) loaded more strongly with the visual span tasks, presumably because auditory-verbal rehearsal was not possible (Gray et al., 2017). These considerations suggest that tying up attention is what prevented participants from processing illustrations in a manner deep enough to retrieve and use the associated meanings of the verbal descriptions, as opposed to just surface grammatical forms. Alternatively, the visual-spatial information could have directly interfered with pictorial processing in some way.

Future studies will continue to explore the interaction of these types of loads with language production by changing up the type of load, requiring more practice on the load, or providing feedback on the load responses in order to further increase motivation for holding the load. We would expect that the loads that require more attention will be the ones to cause more of an effect on language. For example, perhaps requiring participants to remember the notes of a series of tones will be more taxing on attention than remembering the location of a marker.

\section{Conclusions}

We sought to find out how constraining working memory capacity by imposing a memory load would affect the language production of preschool-aged children. We found that working memory loads can affect the syntactic recall of previously heard image descriptions, ironically causing participants to utilize the passive voice more often. We found this effect specifically when there was a visual-spatial load. The findings suggest that when the available resources are limited by a visual-spatial memory load, and to some extent by an auditory-verbal memory load, participants may forego a semantic analysis and instead attempt to repeat a description they heard before verbatim. Sometimes, this strategy for handling a dual task results in semantically incorrect repetitions, usually in the form of 
passive sentences. We know that the productions are not always the product of a mistaken semantic analysis in that the mistakes sometimes occurred in the form of mistakes that children of this age would not make on a semantic basis, e.g., The flower was watered by the girl. Such semantic mistakes were much less likely when there was no memory load, though at the cost of including a higher proportion of active sentences in conflict with the experimenter's instructions.

These findings bear critical implications for the study of language development. Though language input and possibly hard-wired learning strategies definitely contribute in the growth of language abilities, working memory capacity is necessary for successful functioning. The ability to perform more complex language tasks (e.g., reformulating sentences into different syntactic forms) requires working memory capacity, which increases with age. This increase in working memory capacity then allows for the ability to use more complex language with development. Future studies should experimentally examine how working memory availability is related to other aspects of language to explore the cognitive basis of language development.

\section{Supplementary Material}

Refer to Web version on PubMed Central for supplementary material.

\section{References}

Acheson DJ, \& MacDonald MC (2009). Verbal working memory and language production: Common approaches to the serial ordering of verbal information. Psychological bulletin, 135(1), 50 . [PubMed: 19210053]

Adams AM, \& Gathercole SE (1996). Phonological working memory and spoken language development in young children. The Quarterly Journal of Experimental Psychology: Section A, 49(1), 216-233.

Adams EJ, Nguyen AT, \& Cowan N (2018). Theories of working memory: Differences in definition, degree of modularity, role of attention, and purpose. Language, Speech, and Hearing Services in Schools, 49, 340-355.

Ambridge B, Kidd E, Rowland CF, \& Theakston AL (2015). The ubiquity of frequency effects in first language acquisition. Journal of Child Language, 42(2), 239-273. [PubMed: 25644408]

Ang SY, \& Lee K (2008). Central executive involvement in children's spatial memory. Memory, 16, 918-933. [PubMed: 18802804]

Archibald L (2018). The reciprocal Influences of working memory and linguistic knowledge on language performance: Considerations for the assessment of children with developmental language disorder. Language, Speech, and Hearing Services in Schools, 49, 424-433.

Baddeley AD (1986). Working memory. Oxford, England: Clarendon Press.

Baldie BJ (1976). The acquisition of the passive voice. Journal of Child Language, 3(3), 331-348.

Bird H, Franklin S, \& Howard D (2001). Age of acquisition and imageability ratings for a large set of words, including verbs and function words. Behavior Research Methods, Instruments, \& Computers, 33(1), 73-79.

Bourdin B, \& Fayol M (1994). Is written language production more difficult than oral language production? A working memory approach. International journal of psychology, 29(5), 591-620.

Camos V, Mora G, \& Oberauer K (2011). Adaptive choice between articulatory rehearsal and attentional refreshing in verbal working memory. Memory \& Cognition, 39, 231-244. [PubMed: 21264630] 
Caplan D, Waters G, \& DeDe G, (2007). Specialized verbal working memory for language comprehension. In Conway ARA, Jarrold C, Kane MJ, Miyake A, \& Towse J (eds), Variation in working memory. New York, NY: Oxford University Press. (pp. 272-302)

Cowan N (2014). Working memory underpins cognitive development, learning, and education. Educational Psychology Review, 26(2), 197-223. [PubMed: 25346585]

Cowan N (2016). Working memory maturation: Can we get at the essence of cognitive growth? Perspectives on Psychological Science, 11(2), 239-264. [PubMed: 26993277]

Cowan N (2017). The many faces of working memory and short-term storage. Psychonomic Bulletin \& Review, 24(4), 1158-1170. [PubMed: 27896630]

Daneman M, \& Carpenter PA (1980). Individual differences in working memory and reading. Journal of verbal learning and verbal behavior, 19(4), 450-466.

Delage H, \& Frauenfelder UH (2019). Syntax and working memory in typically-developing children: Focus on syntactic complexity. Language, Interaction and Acquisition, 10 (2), 141-176.

Dunn LM, \& Dunn DM (2007). PPVT-4: Peabody picture vocabulary test. Pearson Assessments.

Fromkin VA (1973). Slips of the tongue. Scientific American, 229(6), 110-117. [PubMed: 4756435]

Gerken L, Landau B, \& Remez RE (1990). Function morphemes in young children's speech perception and production. Developmental psychology, 26(2), 204.

Gleitman LR, Gleitman H, \& Shipley EF (1972). The emergence of the child as grammarian. Cognition, 1, 137-174.

Gray S, Green S, Alt M, Hogan T, Kuo T, Brinkley S, \& Cowan N (2017). The structure of working memory in young school-age children and its relation to intelligence. Journal of Memory and Language, 19,183-201.

Hakuta K (1982). Interaction between particles and word order in the comprehension and production of simple sentences in Japanese. Developmental Psychology, 18, 62-76.

Harris M (1976). The influence of reversibility and truncation on the interpretation of the passive voice by young children. British Journal of Psychology, 67(3), 419-427.

Hartsuiker RJ, \& Barkhuysen PN (2006). Language production and working memory: The case of subject-verb agreement. Language and Cognitive Processes, 21(1-3), 181-204.

Huang YT, Leech K, \& Rowe ML (2017). Exploring socioeconomic differences in syntactic development through the lens of real-time processing. Cognition, 159, 61-75. [PubMed: 27888690]

Huang YT, Zheng X, Meng X, \& Snedeker J (2013). Children's assignment of grammatical roles in the online processing of Mandarin passive sentences. Journal of Memory and Language, 69(4), 589-606.

Hutson BA, \& Powers J (1974). Reversing irreversible sentences: Semantic and syntactic factors. Journal of Reading Behavior, 6(1), 99-110.

Huttenlocher J, Vasilyeva M, \& Shimpi P (2004). Syntactic priming in young children. Journal of memory and language, 50(2), 182-195.

JASP Team (2019). JASP (Version 0.11.1) [Computer software].

Just MA, \& Carpenter PA (1992). A capacity theory of comprehension: individual differences in working memory. Psychological review, 99(1), 122. [PubMed: 1546114]

Kuperman V, Stadthagen-Gonzalez H, \& Brysbaert M (2012). Age-of-acquisition ratings for 30,000 English words. Behavior Research Methods, 44(4), 978-990. [PubMed: 22581493]

Marton K, \& Schwartz RG (2003). Working memory capacity and language processes in children with specific language impairment. Journal of Speech, Language, and Hearing Research, 46(5), $1138-1153$.

McCutchen D (1996). A capacity theory of writing: Working memory in composition. Educational Psychology Review, 8(3), 299-325.

Morey CC, \& Bieler M (2013). Visual short-term memory always requires attention. Psychonomic Bulletin \& Review, 20, 163-170. [PubMed: 23002024]

Rouder JN, Morey RD, Speckman PL, and Province JM (2012). Default Bayes factors for ANOVA designs. Journal of Mathematical Psychology, 56, 356-374. 
Rouder JN, Speckman PL, Sun D, Morey RD, \& Iverson G (2009). Bayesian t Tests for Accepting and Rejecting the Null Hypothesis. Psychonomic Bulletin \& Review, 16, 225-237. [PubMed: 19293088]

Segalowitz NS, \& Galang RG (1978). Agent-patient word-order preference in the acquisition of Tagalog. Journal of Child Language, 5, 47-64

Szekely A, Jacobsen T, D’Amico S, Devescovi A, Andonova E, Herron D, ... \& Federmeier K. (2004). A new on-line resource for psycholinguistic studies. Journal of memory and language, 51(2), 247-250. [PubMed: 23002322]

Sinclair A, Sinclair H, \& De Marcelus O (1971). Young children's comprehension and production of passive sentences. Archives de psychologie. Turner EA, \& Rommetveit R. (1967). The acquisition of sentence voice and reversibility. Child Development, 649-660.

Williams K (2007). Expressive vocabulary test-Second edition. Circle Pines, MN: AGS. 

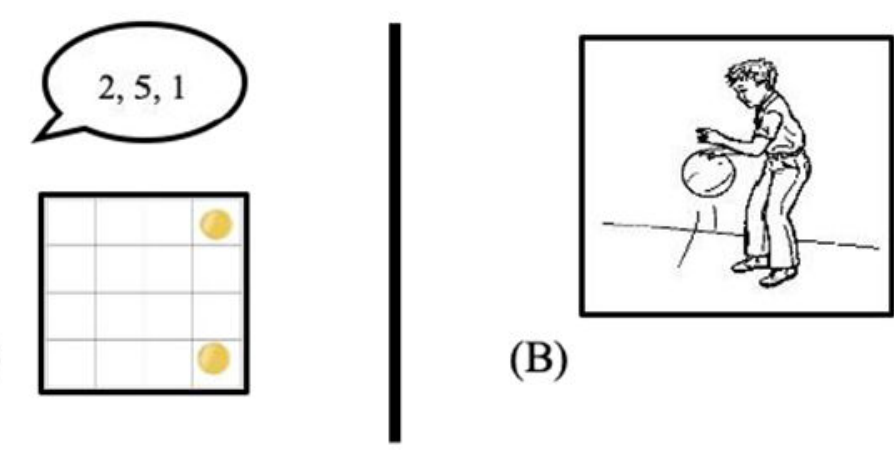

(B)

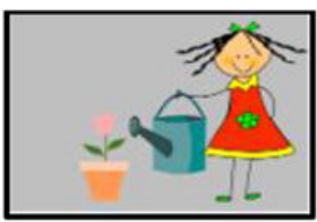

(A)

(C)
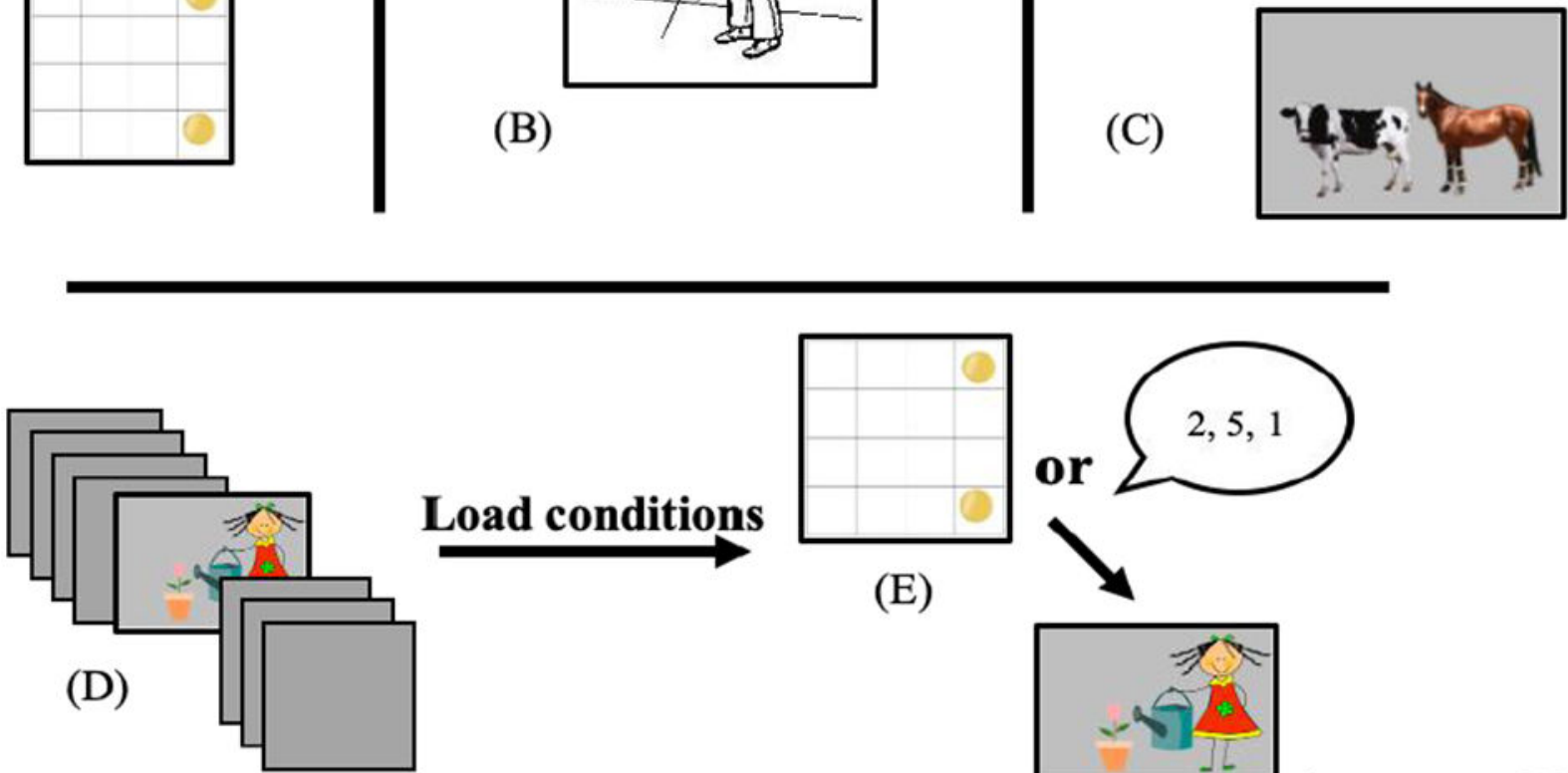

Load conditions

No load condition

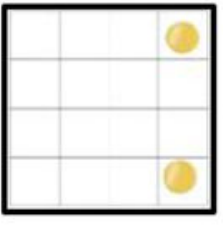

(E)
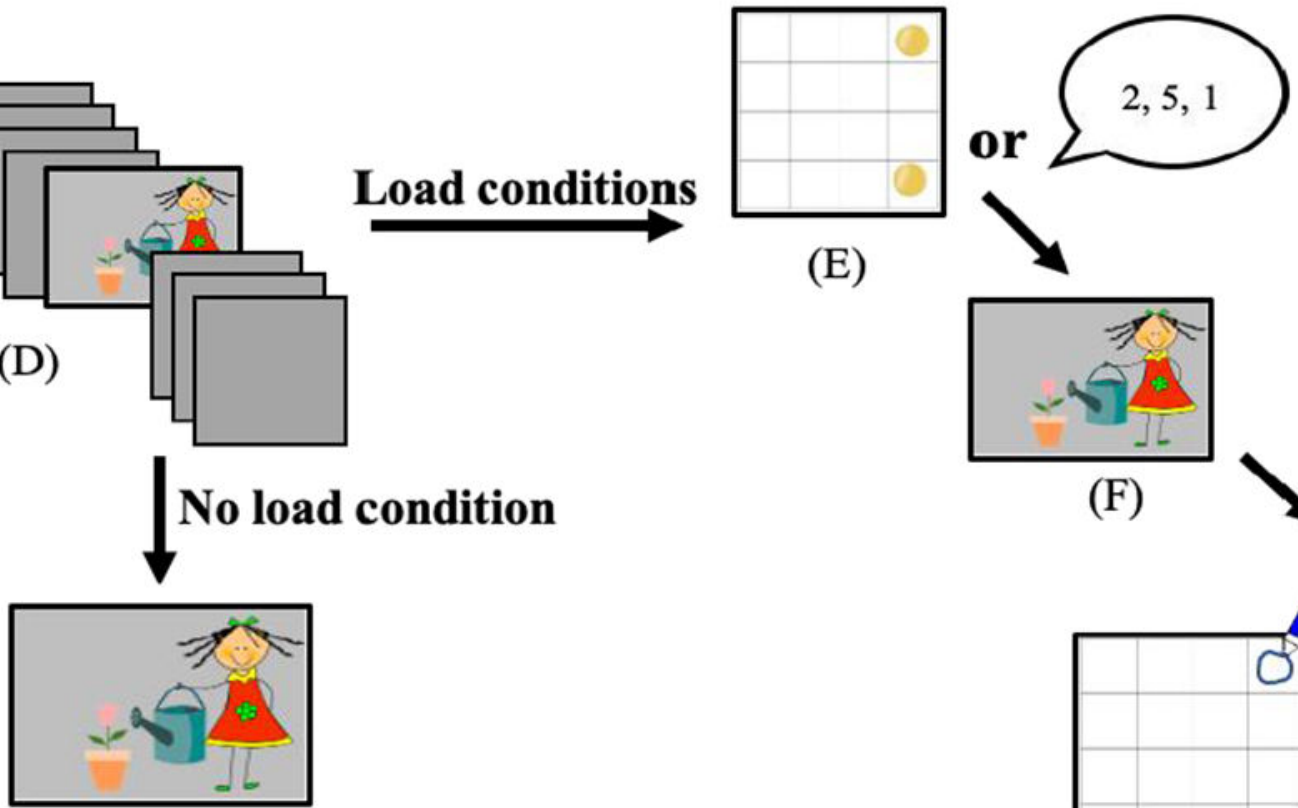

(H)

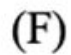

(F)

$2, \ldots$

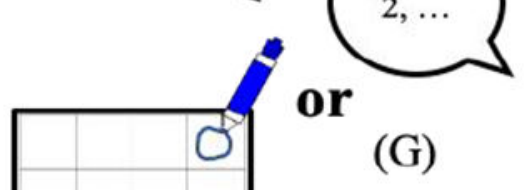

Figure 1.

Illustration of method in both experiments. Top: Examples of stimulus materials. (A) Load materials: auditory-verbal load and visual-spatial load (B) Example of an image used in Experiment 1. (C) Examples of images used for Experiment 2. Top, an irreversible example. Bottom, a reversible example. Bottom: Example of single trial under each load type. (A) Experimenter describes target image in the passive voice (among descriptions of 8 images). (B) Participant receives load to be remembered. (C) While keeping the load from $(B)$ in mind, the participant is shown the target image and is to recall what occurred. (D) After describing target image, the participant recalls the load from $(B)$ by either drawing tokens or saying the numbers out loud. (E) In a no-load trial, participants would simply describe the target image (among other trials) after hearing the experimenter's descriptions. 

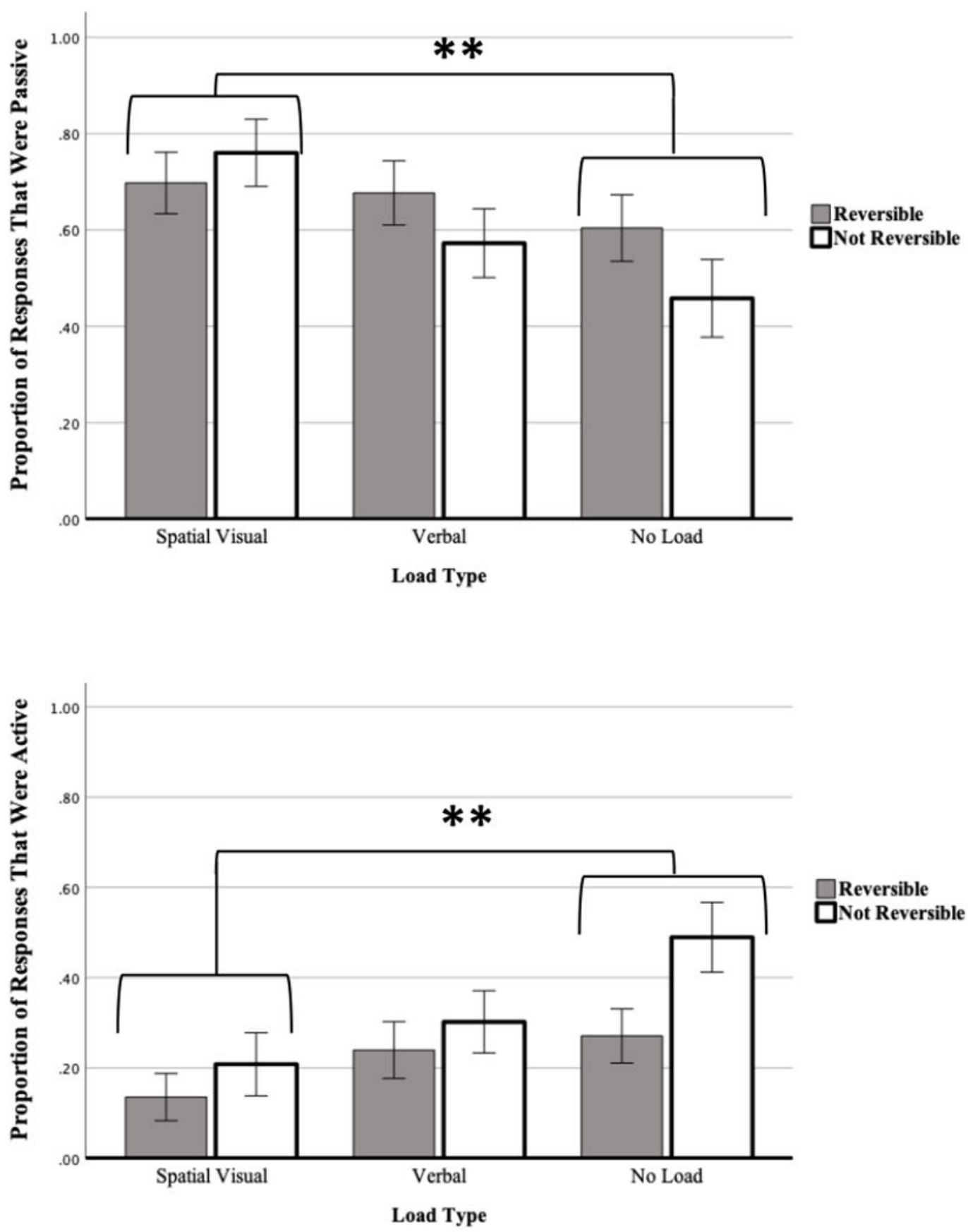

Figure 2.

Proportion of responses of a particular type out of all responses, separately by load condition (x axis) and sentence reversibility (graph parameter). Top panel: Proportion of passive sentence responses. Bottom panel: Proportion of active sentence responses. Error bars are standard error of the mean. These results include both correct and erroneous use of passive and active sentence structure. Reversible items included those in which the subject and object can switch in sentence position and maintain logic. 


\section{3 (A) Incorrect Responses}

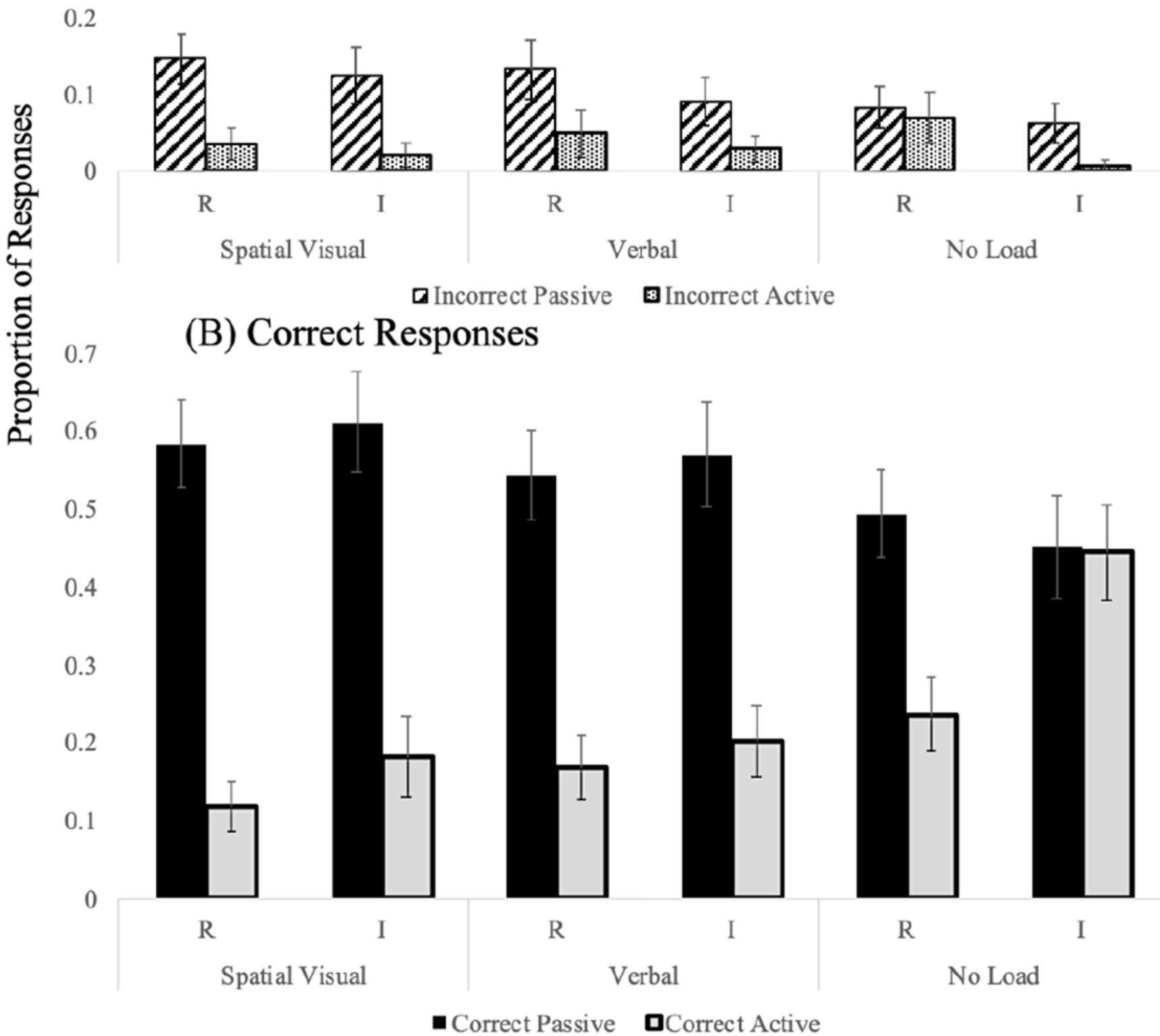

Figure 3.

Proportion of responses for each combination of load type and sentence reversibility, limited to (A) incorrect responses, which included errors semantically deviant from the adult model, and (B) correct responses, which were semantically true to the model. The first and second bar in each pair reflects passive and active sentence forms in the response, respectively. Note the increase in the use of the active in the case of no load. R=reversible. I=Irreversible. 